\title{
Association between the Occurrence of Adenomyosis and the Clinical Outcomes of Vaginal Repair of Cesarean Scar Defects: An Observational Cohort Study
}

\author{
Huihui Chen ${ }^{1}$, Wenjing Wang ${ }^{1}$, Husheng Wang ${ }^{1}$, and Xipeng Wang ${ }^{1}$ \\ ${ }^{1}$ Affiliation not available
}

September 17, 2020

\begin{abstract}
Study Objective: To examine the correlation between the occurrence of adenomyosis and the outcome of vaginal repair of cesarean scar defects (CSD). Design: A retrospective observational cohort study. Setting: University hospital. Patients: A total of 278 women with CSD were enrolled at the Shanghai First Maternity \& Infant Hospital between January 2013 and August 2017. Interventions: Vaginal excision and suture of CSD. Measures and Main Results: According to preoperative magnetic resonance imaging (MRI) findings, patients were divided into two groups, the adenomyosis group (group A) and the non-adenomyosis group (group B). For group A patients, the mean duration of menstruation at 3- and 6-months follow-up was shorter and the TRM at the median-month follow-up was significantly thinner than those in group B patients $(\mathrm{p}<0.05)$. There were more patients with class-A healing in group B compared with group A $(44.7 \%$ vs $30.0 \%$; p < 0.05). Furthermore, $59.3 \%$ $(32 / 54)$ of women tried to conceive after vaginal repair. The pregnancy rates of women with and without adenomyosis were $66.7 \%(8 / 12)$ and $61.9 \%(26 / 42)$, respectively. The duration of menstruation decreased significantly from $13.4 \pm 3.3$ days to $7.6 \pm 2.3$ days after vaginal repair in 25 patients $(\mathrm{p}<0.001)$. The TRM increased significantly from $2.3 \pm 0.8 \mathrm{~mm}$ to $7.6 \pm$ $2.9 \mathrm{~mm}$ after vaginal repair $(\mathrm{p}<0.001)$. Conclusion: Vaginal repair reduced postmenstrual spotting and improve fertility in patients with CSD. Adenomyosis might be an adverse factor in the repair of uterine incisions.
\end{abstract}

\section{Introduction}

With the increase in the number of cesarean sections in the past three decades, cesarean scar defects (CSDs), as a new type of iatrogenic disease, have gained enormous research momentum. CSD was first described by Morris in 1995 as a pouch-like defect in the anterior uterine wall at the site of a previous cesarean section $^{1}$. Many patients with CSD are asymptomatic; however, many have reported intermenstrual spotting, dysmenorrhea, dyspareunia, and chronic pelvic pain. Other studies have reported that CSD is an adverse factor for uterine rupture and infertility ${ }^{2-5}$.

Magnetic resonance imaging (MRI) and transvaginal sonography (TVS) are useful in the diagnosis of CSD, and both methods can determine the length, width, and depth of the defect and the thickness of the residual myometrium (TRM). In addition, MRI is useful in diagnosing other gynecological diseases such as fibroids, adenomyosis, ovarian tumors, and pelvic diseases.

Adenomyosis, as one of the manifestations of endometriosis that affects women of child-bearing age, is categorized by the presence of hypertrophic smooth muscle derived from ectopic endometrial glands and stroma within the myometrium ${ }^{6,7}$. The main symptoms of adenomyosis are menorrhagia, dysmenorrhea, recurrent implantation failure, and miscarriage ${ }^{8}$.

MRI and TVS are commonly used in the diagnosis adenomyosis ${ }^{9}$. However, the sensitivity (88\%), specificity (94.6\%), and diagnostic accuracy (85-90.8\%) of MRI are greater than those of TVS ${ }^{10,11}$. In addition, 
the positive predictive value (PPV) and negative predictive value (NPV) of MRI were $95.6 \%$ and $85.4 \%$, respectively ${ }^{11}$.

Vaginal repair due to CSDs is a minimally invasive and effective method that maintains fertility ${ }^{12-14}$. Patients suffering from intermittent postmenstrual bleeding that underwent vaginal repair still had CSDs, although the size of the defect and the clinical symptoms were improved significantly. In another study, adenomyosis was reported to involve repeated auto-traumatization and self-healing of the endometrial-myometrial junctional zone, thereby affecting myometrium healing ${ }^{15}$. This has prompted us to examine the factors involved in the less-than-optimal outcome of vaginal repair.

Here, we hypothesize that adenomyosis might be an adverse factor for uterine repair. We retrospectively reviewed MRI findings of patients with CSDs to determine whether there is a correlation between the occurrence of adenomyosis and the outcome of vaginal repair. We also provide clinical recommendations for the treatment of CSDs.

\section{Patients and methods}

This retrospective study was approved by the ethics committee of the Shanghai First Maternity \& Infant Hospital (KS1512). We retrieved data of 331 outpatients with CSDs who underwent MRI to determine the length, width, and depth of the defect and subsequent vaginal surgery at the Tongji University-affiliated Shanghai First Maternity \& Infant Hospital from January 2013 to August 2017. All MRI scans were reevaluated by an experienced radiologist. After educating patients on the advantages and disadvantages of vaginal surgery, patients provided written informed consent. According to the findings of preoperative MRI scans, patients were divided into two groups, the adenomyosis group (group A) and the non-adenomyosis group (group B).

The inclusion criteria were patients who had one or more cesarean deliveries, patients who had intermenstrual spotting after the cesarean section or those in which the TRM was less than $3.0 \mathrm{~mm}$ at the preoperative stage, and patients who underwent MRI and TVS to evaluate the size of the defect and the TRM before surgery (Fig. S1). Patients who had a history of endocrine disorders, menstrual irregularities before cesarean section, coagulation disorders, use of intrauterine devices, sub-mucous myoma, endometrial diseases, endometrial cysts, uterine fibroids, and adenomyosis after cesarean section were excluded from this study.

\section{Surgical procedures}

All surgical procedures were performed by an experienced surgeon as previously described ${ }^{12,13,16}$. After administering continuous epidural anesthesia, patients were placed in the bladder lithotomy position. The bladder was empty in all patients. The anterior peritoneal reflection was opened, and the abdominal cavity was entered. After exposing the lower uterine segment, a probe was used to identify the CSD area. The tissue was trimmed with scissors to reveal the healthy myometrium, and the CSD tissue was completely removed. The myometrium was closed using a double-layer closure of 1-0 absorbable sutures with an interrupted suture (Fig. S2).

\section{Magnetic resonance imaging}

MRI scans were conducted with a 1.5 T MR scanner (Optima MR360; General Electric Company, USA). The patients underwent routine screening of pelvic sagittal and coronal planes and fat-suppressed sagittal and coronal planes. All images were evaluated by an experienced radiologist. Several baseline characteristics were assessed on T2-weighted images, including the position of the uterus (anteverted or retroverted); diameter of the CSD (the length, width, and depth); the TRM; and the presence of adenomyosis, endometriosis, or uterine fibroids.

The main features of adenomyosis were an increased thickness of the junctional zone of the uterus (exceeding $12 \mathrm{~mm}$ ), and the presence of intramyometrial cyst(s) or a heterogeneous myometrium, which were associated with heterogeneously hyperintense regions on T2-weighted, and sometimes T1-weighted, images (Fig. S3).

\section{Data collection and follow-up}


Data were identified using diagnostic codes in billing records. Preoperative and postoperative clinical information was collected, including age; other general patient details; number of cesarean sections; history of menstrual conditions; position of the uterus; hemoglobin level on the first postoperative day; length of hospitalization; hospitalization cost; and CSD length, width, and depth; and the TRM. All patients were required to undergo examinations at 3 - and 6 -months after surgery to obtain information on menstruation, measure the CSD scar, and undergo MRI or TVS. Patients who failed to return in a timely manner were followed-up by telephone. Information was collected from patients by telephone who tried to become pregnant.

\section{Statistical analysis}

SPSS 22.0 software (SPSS Inc., Chicago, IL, USA) was used for all statistical analyses. Data are presented as the means $\pm \mathrm{SD}$ or percentages as appropriate. A paired $t$-test was used to analyze preoperative and postoperative data. Continuous data are presented as medians and ranges, and categorical data are presented as frequencies and percentages. The hospitalization length and hospitalization cost were analyzed using the Mann-Whitney U test. Categorical variables were analyzed using the chi-squared test or Fisher's exact test when the number of variables was less than five. $P$-values $<0.05$ were considered to be statistically significant.

\section{Results}

\section{Patient characteristics}

The pretreatment demographic data are summarized in Table S1. A total of 278 patients were enrolled and divided into the adenomyosis group (group $\mathrm{A}, n=50$ ), in which the mean patient age was $32.6 \pm 3.8$ years, and the non-adenomyosis group (group B, $n=228$ ), in which the mean patient age was $32.8 \pm 3.6$ years. No significant differences were observed in the number of cesarean sections; duration of postmenstrual spotting before cesarean section; mean preoperative CSD length, width, and depth; and the TRM measured by TVS between the groups $(p>0.05)$. However, the duration of postmenstrual spotting after cesarean section in group A patients was significantly longer than that in group B patients $(15.3 \pm 4.1$ days versus $14.0 \pm 3.2$ days, $p<0.05)$. In addition, the mean preoperative width was significantly longer and the TRM was thicker in group A patients than that in group B patients $(15.0 \pm 3.7 \mathrm{~mm}$ versus $16.6 \pm 4.4 \mathrm{~mm} ; 2.9 \pm 1.1 \mathrm{~mm}$ versus $2.5 \pm 1.2 \mathrm{~mm}, \mathrm{p}<0.05)$.

\section{Clinical outcomes after surgery}

All patients underwent vaginal repair. The clinical data are summarized in Table S2. No significant differences in the duration of the surgical procedure, hospitalization stay, and hospitalization cost were observed between the groups $(p>0.05)$. However, the hemoglobin level on the first postoperative day was significantly higher in group-B patients than that in group-A patients $(106.0 \pm 11.2 \mathrm{~g} / \mathrm{L}$ vs $99.5 \pm 13.4 \mathrm{~g} / \mathrm{L}, p<0.05)$. In addition, four out of 228 patients in group B had complications (two cases of bladder injury and two cases of hematoma), whereas one out of 50 patients in group A had a complication (hematoma). Thus, the incidence of perioperative complications was $1.8 \%$ and $2.0 \%$ in the two groups, respectively.

\section{Gynecological follow-up}

Data on the duration of menstruation and the TRM before and after surgery are summarized in Table S3. A total of 231 patients and 191 patients were examined at 3- and 6-months after surgery. For group B patients, the mean durations of menstruation at 3 - and 6 -months follow-up were significantly shorter than those before surgery $(8.1 \pm 2.5$ days and $8.3 \pm 2.4$ days, respectively, $p<0.05)$. For group A patients, the mean durations of menstruation at 3- and 6-months follow-up were significantly shorter than those before surgery $(p<0.05)$. The TRM at the median-month follow-up was significantly strengthen in both groups $(p<0.05)$

Data on the durations of menstruation at 3- and 6-months follow-up are summarized in Table S4. At 3- and 6-months follow-up, the mean durations of menstruation were $8.1 \pm 2.3$ days and $8.1 \pm 1.6$ days, respectively, and no significant difference was observed between the two groups $(p>0.05)$. Subsequently, we considered 7 days as the mean duration of menstruation and divided the patients into two subgroups. We found that $55.3 \%(126 / 228)$ of patients in group B had an optimal duration of menstruation (i.e., 7 days) at 3- and 
6-months follow-up compared to 38.0\% (19/50) of patients in group A $(p<0.05)$. At 3 - and 6-months followup, 183 group-A patients and 138 group B patients underwent MRI. No significant difference was observed in the CSD length, width, and depth, and the TRM of the CSD was thinner after vaginal repair $(p>0.05)$. Class-A healing was defined as a duration of menstruation of no more than 7 days and a TRM of no less than $5.8 \mathrm{~mm}$ after vaginal repair ${ }^{17}$. Class-A healing was more prevalent in group-B patients compared to group-A patients $(44.7 \%$ vs $30.0 \% ; p<0.05)$.

\section{Pregnancy follow-up}

The pregnancy outcome was assessed in 32 out of 54 women (59.3\%) who attempted to conceive after vaginal repair (Fig. S4). Among these, there were 12 cases of adenomyosis and 42 cases of non-adenomyosis. For those that achieved pregnancy, the pregnancy rates of women with and without adenomyosis were $66.7 \%(8 / 12)$ and $61.9 \%$ (26/42), respectively. Unfortunately, seven out of 54 pregnancies (13.0\%) resulted in miscarriages, which included two women with adenomyosis and five women without adenomyosis. Due to privacy concerns, two out of 26 women without adenomyosis did not want to reveal details of their pregnancies. Data on 25 women (six with adenomyosis and 19 without adenomyosis) who achieved pregnancy and delivered infants are summarized in Table S5. By TVS, the TRM increased significantly from $2.3 \pm 0.8 \mathrm{~mm}$ (range, 0.5-4.0 $\mathrm{mm}$ ) to $7.6 \pm 2.9 \mathrm{~mm}$ (range, $3.0-12.0 \mathrm{~mm}$ ) after vaginal repair at the 3 -month follow-up $(p<0.001)$. The duration of menstruation decreased significantly from $13.4 \pm 3.3$ days to $7.6 \pm 2.3$ days after vaginal repair $(p<0.001)$. At the 3-month follow-up, 17 out of $25(68.0 \%)$ women had no evidence of CSD as determined by TVS. All women selected cesarean section as the method of childbirth, and there was no case of uterine rupture or dehiscence. As shown in Table S5, the mean neonatal birth weight was $3224.2 \pm 401.0 \mathrm{~g}$ for the women who gave birth. Two women without adenomyosis suffered postpartum hemorrhage. However, all women had good pregnancy outcomes and delivered healthy babies.

\section{Discussion}

Three decades ago, the World Health Organization (WHO) suggested that the rate of cesarean sections be maintained at $15 \%^{18}$. However, the rate of cesarean sections continues to increase, resulting in more severe complications such as abdominal bleeding, chronic pelvic pain, uterine scar pregnancy, placenta accrete, and uterine rupture due to incomplete healing of cesarean section scars. Effective treatments for CSD include laparotomy, laparoscopy, hysteroscopy, and vaginal repair. However, the outcomes of surgical intervention are not always successful, and there is no consensus on which surgical intervention is the best ${ }^{19}$. Our center is the largest vaginal repair center in China, and vaginal repair is offered to symptomatic women who wish to preserve the uterus and to asymptomatic women who wish to preserve fertility. A total of 278 patients underwent pre- and postoperative MRI or TVS. We found that gynecological symptoms, such as postmenstrual spotting, and the uterine morphology improved (Table S3). However, some scar defects could not be repaired.

Adenomyosis is a common gynecological disease characterized by the infiltration of ectopic endometrial glands and/or stroma into the myometrium, thereby causing dysmenorrhea, pelvic pain, abnormal uterine bleeding, and infertility ${ }^{6,20,21}$. Fifty out of 278 patients (18.0\%) had adenomyosis, consistent with previous studies reporting an incidence of $20 \%^{22,23}$. The mean preoperative CSD width was smaller and the TRM was thicker in patients with adenomyosis than that in patients without the disorder and this was due to the presence of hyperplastic and hypertrophic smooth muscle.

The duration of menstruation before cesarean section was longer in patients with adenomyosis than that in patients without the disorder; however, the results were not statistically different $(p>0.05)$. These patients suffered abnormal uterine bleeding after cesarean delivery. In addition, the duration of menstruation after cesarean section was significantly longer in patients with adenomyosis than that in patients without the disorder $(p<0.05)$, suggesting that adenomyosis might disrupt the tissue repair process. At follow-up, the duration of menstruation was optimal in patients with adenomyosis $(p<0.05)$. Furthermore, the optimal rate of class A healing after vaginal repair was not achieved in patients with adenomyosis (Table S4), revealing that adenomyosis was an adverse factor in the healing of uterine incisions. 
Ectopic endometrial glands and the presence of stroma can cause repeated bleeding of the myometrium. Repeated tissue injury and repair caused by adenomyotic lesions increases the degree of fibrosis ${ }^{15}$. Ibrahim et al. reported the presence of myofibroblasts at the endometrial-myometrial junctional zone in the uteri of patients with adenomyosis, suggesting that the tissue injury and repair (TIAR) mechanism was activated 24-26. Estrogen plays important roles in proliferation and healing. In the uterus, estrogen induces uterine peristalsis, thereby further aggravating auto-traumatization. Repeated cycles of auto-traumatization at the endometrial-myometrial junctional zone can disrupt uterine muscular fibers, which eventually leads to endometrial basalis invagination and inhibits the healing process ${ }^{15}$.

Adenomyosis and endometriosis are closely linked and estrogens are involved in both disorders ${ }^{27}$, 28 . Endometriosis creates an inflammatory environment where many different types of chemokines, such chemokine C-X-C motif chemokine ligand 12 (CXCL12), are produced, thereby attracting bone marrow cells to the lesions ${ }^{29}$. The chemokine receptor 4 (CXCR4) and its specific ligand CXCL12 play important roles in the mobilization and homing of stem cells ${ }^{30}$. Compared to the eutopic endometrium, the expression of CXCl12 and CXCR4 was significantly increased in endometriosis, indicating that stem cells were recruited and circulating stem cells were limited ${ }^{29}$.

Stem cells can self-renew and produce more differentiated daughter cells ${ }^{31}, 32$, and these multipotent stem cells can be used in tissue engineering and regenerative medicine ${ }^{33,34}$. Other studies have reported that bone marrow-derived stem cells are involved in uterine repair. Therefore, the repair of uterine damage is dependent on the population of stem cells ${ }^{33}$. Randomized double-blind controlled studies are needed to confirm the correlation between adenomyosis treatment and myometrial repair.

It has been reported that 10 of $18(55.6 \%)$ women who underwent laparoscopic repair achieved pregnancy 35. In another study, eight out of 18 infertile women (44.4\%) became pregnant, delivering healthy babies by cesarean section ${ }^{36}$. A total of $59.3 \%$ of the patients in our study achieved pregnancy after vaginal repair, with eight out of 12 women with adenomyosis achieving pregnancy, which was slightly higher than that in women without the disorder. Furthermore, fertility was not affected in both groups.

Uterine rupture is a catastrophic complication during pregnancy and labor, especially for women with a history of cesarean section. The TRM is an indicator of uterine rupture or dehiscence, and although many risk factors can lead to uterine rupture or dehiscence, there is an association between a thin TRM and uterine rupture or dehiscence ${ }^{37}$. However, the TRM cutoff remains controversial. It has been reported that the cutoff TRM value for the risk of uterine rupture be set at $2.5-3.0 \mathrm{~mm}^{2}, 38,39$. In this study, we found that the TRM of women who achieved pregnancy and delivered infants increased significantly from $2.3 \pm$ $0.8 \mathrm{~mm}$ before surgery to $7.6 \pm 2.9 \mathrm{~mm}$ after surgery, and the TRM was not less than $3 \mathrm{~mm}$. Therefore, the pregnancy outcome was good, and there were no cases of uterine rupture or dehiscence. Furthermore, vaginal repair not only reduced menstrual spotting but also reconstructed the uterus to improve fertility in patients with CSD.

Unfortunately, seven women experienced miscarriages, and $22(40.7 \%)$ women failed to achieve pregnancy. Pregnancy is a complicated process, and the rate of spontaneous miscarriage is $<15 \%$ of all pregnancies 40 . For instance, Giakoumelou et al. reported that miscarriage occurred in one out of five pregnancies in women aged $31-36$ years ${ }^{41}$. In the this study, the pregnancy rate was $66.7 \%(8 / 12)$ and the miscarriage rate was $25.0 \%(2 / 8)$ in women with adenomyosis. Further studies with larger cohorts are needed to clarify the relationship between adenomyosis and pregnancy.

There were several limitations in this study. First, our study was a single-center retrospective study, although the sample size was fairly large. Second, information on the duration of menstruation was obtained by memory, which may have caused bias. Third, the sample size used to generate the data on subsequent pregnancies after treatment was small; therefore, the relationship between adenomyosis and pregnancy could not be assessed. Therefore, further prospective and large multi-center studies are needed in the future.

\section{Conclusion}


Vaginal repair is a minimally invasive surgical procedure that can reduce postmenstrual spotting and repair the uterus to improve fertility in patients with CSD. Adenomyosis might be an adverse factor for the healing of uterine incisions. Randomized double-blind controlled studies are needed to verify the positive correlation between myometrial repair and adenomyosis treatment.

\section{Acknowledgments}

We thank all patients, doctors and nurses who participated in this study.

Disclosure of interests: The authors declare that they have no conflicts of interest and nothing to disclose.

\section{Contribution to authorship:}

CHH: Literature research, Data acquisition, Manuscript preparation

WWJ: Data acquisition, Statistical analysis, Manuscript definition of intellectual content

WHS: Statistical analysis, Data analysis/interpretation, Manuscript editing

WXP: Guarantor of integrity of entire study, Study design, Manuscript revision, Manuscript final version approval

Details of ethics approval: All patients signed the informed consent and the study was approved by the relevant Institutional Review Board (KS1512) of the Ethics Committee, Shanghai First Maternity and infant Hospital, Tongji University School of Medicine. All animal experiments comply with the ARRIVE guidelines and should be carried out in accordance with the National Institutes of Health guide for the care and use of Laboratory animals (NIH Publications No. 8023, revised 1978) and we have followed guidelines.

Funding: This study was supported by grants from The Ministry of Science and Technology of China (2020YFC2002800) and the National Natural Science Foundation of China (81874103 and 81930064).

\section{References:}

1. Morris H. Surgical pathology of the lower uterine segment caesarean section scar: is the scar a source of clinical symptoms? Int J Gynecol Pathol. 1995 Jan;14(1):16-20.

2. Bij de Vaate AJ, van der Voet LF, Naji O, Witmer M, Veersema S, Brolmann HA, et al. Prevalence, potential risk factors for development and symptoms related to the presence of uterine niches following Cesarean section: systematic review. Ultrasound in obstetrics \& gynecology : the official journal of the International Society of Ultrasound in Obstetrics and Gynecology. 2014 Apr;43(4):372-82.

3. Gubbini G, Centini G, Nascetti D, Marra E, Moncini I, Bruni L, et al. Surgical hysteroscopic treatment of cesarean-induced isthmocele in restoring fertility: prospective study. Journal of minimally invasive gynecology. 2011 Mar-Apr;18(2):234-7.

4. Tulandi T, Cohen A. Emerging Manifestations of Cesarean Scar Defect in Reproductive-aged Women. Journal of minimally invasive gynecology. 2016 Sep-Oct;23(6):893-902.

5. Marotta ML, Donnez J, Squifflet J, Jadoul P, Darii N, Donnez O. Laparoscopic repair of post-cesarean section uterine scar defects diagnosed in nonpregnant women. Journal of minimally invasive gynecology. 2013 May-Jun;20(3):386-91.

6. Benagiano G, Habiba M, Brosens I. The pathophysiology of uterine adenomyosis: an update. Fertility and sterility. 2012 Sep;98(3):572-9.

7. Kepkep K, Tuncay YA, Goynumer G, Tutal E. Transvaginal sonography in the diagnosis of adenomyosis: which findings are most accurate? Ultrasound in obstetrics \& gynecology : the official journal of the International Society of Ultrasound in Obstetrics and Gynecology. 2007 Sep;30(3):341-5.

8. Inoue S, Hirota Y, Ueno T, Fukui Y, Yoshida E, Hayashi T, et al. Uterine adenomyosis is an oligoclonal disorder associated with KRAS mutations. Nat Commun. 2019 Dec 19;10(1):5785. 
9. Reinhold C, McCarthy S, Bret PM, Mehio A, Atri M, Zakarian R, et al. Diffuse adenomyosis: comparison of endovaginal US and MR imaging with histopathologic correlation. Radiology. 1996 Apr;199(1):151-8.

10. Novellas S, Chassang M, Delotte J, Toullalan O, Chevallier A, Bouaziz J, et al. MRI characteristics of the uterine junctional zone: from normal to the diagnosis of adenomyosis. AJR Am J Roentgenol. 2011 May;196(5):1206-13.

11. Karamanidis D, Nicolaou P, Chrysafis I, Georgopoulos A, Tarres E, Koutsougeras G. OC01: Transvaginal ultrasonography compared with magnetic resonance imaging for the diagnosis of adenomyosis. Ultrasound in obstetrics \& gynecology : the official journal of the International Society of Ultrasound in Obstetrics and Gynecology. 2018 Oct;52(4):555.

12. Zhou J, Yao M, Wang H, Tan W, Chen P, Wang X. Vaginal Repair of Cesarean Section Scar Diverticula that Resulted in Improved Postoperative Menstruation. Journal of minimally invasive gynecology. 2016 SepOct;23(6):969-78.

13. Zhou X, Yao M, Zhou J, Tan W, Wang H, Wang X. Defect width: the prognostic index for vaginal repair of cesarean section diverticula. Archives of gynecology and obstetrics. 2017 Mar;295(3):623-30.

14. Chen Y, Chang Y, Yao S. Transvaginal management of cesarean scar section diverticulum: a novel surgical treatment. Medical science monitor : international medical journal of experimental and clinical research. 2014 Aug 8;20:1395-9.

15. Garcia-Solares J, Donnez J, Donnez O, Dolmans MM. Pathogenesis of uterine adenomyosis: invagination or metaplasia? Fertility and sterility. 2018 Mar;109(3):371-9.

16. Chen H, Wang H, Zhou J, Xiong Y, Wang X. Vaginal Repair of Cesarean Section Scar Diverticula Diagnosed in Non-pregnant Women. Journal of minimally invasive gynecology. 2019 Mar - Apr;26(3):526-34.

17. Wang Y, Zhu Q, Lin F, Xie L, Li J, Wang X. Development and internal validation of a Nomogram for preoperative prediction of surgical treatment effect on cesarean section diverticulum. BMC Womens Health. 2019 Nov 11;19(1):136.

18. Robson SJ, de Costa CM. Thirty years of the World Health Organization's target caesarean section rate: time to move on. Med J Aust. 2017 Mar 6;206(4):181-5.

19. Setubal A, Alves J, Osorio F, Guerra A, Fernandes R, Albornoz J, et al. Treatment for Uterine Isthmocele, A Pouchlike Defect at the Site of a Cesarean Section Scar. Journal of minimally invasive gynecology. 2018 Jan;25(1):38-46.

20. Naftalin J, Hoo W, Pateman K, Mavrelos D, Foo X, Jurkovic D. Is adenomyosis associated with menorrhagia? Human reproduction. 2014 Mar;29(3):473-9.

21. Vercellini P, Consonni D, Dridi D, Bracco B, Frattaruolo MP, Somigliana E. Uterine adenomyosis and in vitro fertilization outcome: a systematic review and meta-analysis. Human reproduction. 2014 May;29(5):96477.

22. Vercellini P, Parazzini F, Oldani S, Panazza S, Bramante T, Crosignani PG. Adenomyosis at hysterectomy: a study on frequency distribution and patient characteristics. Hum Reprod. 1995 May;10(5):1160-2.

23. Agostinho L, Cruz R, Osorio F, Alves J, Setubal A, Guerra A. MRI for adenomyosis: a pictorial review. Insights Imaging. 2017 Dec;8(6):549-56.

24. Leyendecker G, Bilgicyildirim A, Inacker M, Stalf T, Huppert P, Mall G, et al. Adenomyosis and endometriosis. Re-visiting their association and further insights into the mechanisms of auto-traumatisation. An MRI study. Archives of gynecology and obstetrics. 2015 Apr;291(4):917-32.

25. Leyendecker G, Wildt L. A new concept of endometriosis and adenomyosis: tissue injury and repair (TIAR). Hormone molecular biology and clinical investigation. 2011 Mar 1;5(2):125-42. 
26. Leyendecker G, Wildt L, Mall G. The pathophysiology of endometriosis and adenomyosis: tissue injury and repair. Archives of gynecology and obstetrics. 2009 Oct;280(4):529-38.

27. Chapron C, Tosti C, Marcellin L, Bourdon M, Lafay-Pillet MC, Millischer AE, et al. Relationship between the magnetic resonance imaging appearance of adenomyosis and endometriosis phenotypes. Human reproduction. 2017 Jul 1;32(7):1393-401.

28. Guzel AI, Akselim B, Erkilinc S, Kokanali K, Tokmak A, Dolmus B, et al. Risk factors for adenomyosis, leiomyoma and concurrent adenomyosis and leiomyoma. J Obstet Gynaecol Res. 2015 Jun;41(6):932-7.

29. Moridi I, Mamillapalli R, Cosar E, Ersoy GS, Taylor HS. Bone Marrow Stem Cell Chemotactic Activity Is Induced by Elevated CXCl12 in Endometriosis. Reprod Sci. 2017 Apr;24(4):526-33.

30. Hopman RK, DiPersio JF. Advances in stem cell mobilization. Blood Rev. 2014 Jan;28(1):31-40.

31. Gargett CE. Uterine stem cells: what is the evidence? Human reproduction update. 2007 JanFeb;13(1):87-101.

32. Bongso A, Richards M. History and perspective of stem cell research. Best Pract Res Clin Obstet Gynaecol. 2004 Dec;18(6):827-42.

33. Figueira PG, Abrao MS, Krikun G, Taylor HS. Stem cells in endometrium and their role in the pathogenesis of endometriosis. Ann N Y Acad Sci. 2011 Mar;1221:10-7.

34. Santamaria X, Mas A, Cervello I, Taylor H, Simon C. Uterine stem cells: from basic research to advanced cell therapies. Human reproduction update. 2018 Nov 1;24(6):673-93.

35. Tanimura S, Funamoto H, Hosono T, Shitano Y, Nakashima M, Ametani Y, et al. New diagnostic criteria and operative strategy for cesarean scar syndrome: Endoscopic repair for secondary infertility caused by cesarean scar defect. The journal of obstetrics and gynaecology research. 2015 Sep;41(9):1363-9.

36. Donnez O, Donnez J, Orellana R, Dolmans MM. Gynecological and obstetrical outcomes after laparoscopic repair of a cesarean scar defect in a series of 38 women. Fertility and sterility. 2017 Jan;107(1):289-96 $\mathrm{e} 2$.

37. Vikhareva Osser O, Valentin L. Clinical importance of appearance of cesarean hysterotomy scar at transvaginal ultrasonography in nonpregnant women. Obstetrics and gynecology. 2011 Mar;117(3):525-32.

38. Bujold E, Jastrow N, Simoneau J, Brunet S, Gauthier RJ. Prediction of complete uterine rupture by sonographic evaluation of the lower uterine segment. American journal of obstetrics and gynecology. 2009 Sep;201(3):320 e1-6.

39. Donnez O, Jadoul P, Squifflet J, Donnez J. Laparoscopic repair of wide and deep uterine scar dehiscence after cesarean section. Fertility and sterility. 2008 Apr;89(4):974-80.

40. O'Neill SM, Kearney PM, Kenny LC, Khashan AS, Henriksen TB, Lutomski JE, et al. Caesarean delivery and subsequent stillbirth or miscarriage: systematic review and meta-analysis. PloS one. 2013;8(1):e54588.

41. Giakoumelou S, Wheelhouse N, Cuschieri K, Entrican G, Howie SE, Horne AW. The role of infection in miscarriage. Human reproduction update. 2016 Jan-Feb;22(1):116-33.

Table S1 Patient baseline characteristics prior to treatment

\begin{tabular}{llll}
\hline Demographic & Group A $(\mathrm{n}=50)$ & Group B $(\mathrm{n}=228)$ & $P$ value \\
\hline Age $(\mathrm{y})$ & $32.6 \pm 3.8(23-41)$ & $32.8 \pm 3.6(23-42)$ & .735 \\
Gravidity (n) & $2.2 \pm 1.1(1-5)$ & $2.0 \pm 1.1(1-6)$ & .175 \\
Number of cesarean & $1.4 \pm 0.5(1-3)$ & $1.3 \pm 0.5(1-3)$ & .089 \\
deliveries (n) & & &
\end{tabular}




\begin{tabular}{llll}
\hline Demographic & Group A (n=50) & Group B (n=228) & $P$ value \\
\hline $\begin{array}{l}\text { Duration of } \\
\text { menstruation before }\end{array}$ & $6.3 \pm 1.3(3-10)$ & $6.2 \pm 1.1(3-9)$ & .793 \\
cesarean delivery (d) & & & \\
Duration of & $15.3 \pm 4.1(5-25)$ & $14.0 \pm 3.2(5-30)$ & .013 \\
postmenstrual spotting & & & \\
after cesarean delivery & & & \\
(prior to surgical repair & & & \\
of CSD) (d) & & $99(43.4 \%)$ & .244 \\
Uterus position & $25(50.0 \%)$ & $129(56.6 \%)$ & \\
anteflexion & $25(50.0 \%)$ & & \\
retroflexion & & $12.0 \pm 3.5(2.0-18.0)$ & .640 \\
TVS findings (mm) & $7.7 \pm 3.3(2.0-17.0)$ & $6.4 \pm 2.8(2.0-18.0)$ & .911 \\
CSD length & $12.2 \pm 4.4(3.0-23.0)$ & .177 \\
CSD width & $7.1 \pm 3.4(2.0-19.0)$ & $2.7 \pm 1.1(0.7-7.0)$ & .253 \\
CSD depth & $2.9 \pm 1.4(1.0-9.0)$ & & \\
TRM & & & \\
MRI findings (mm) & $9.3 \pm 3.8(1.0-18.5)$ & $9.1 \pm 3.2(1.0-20.0)$ & .653 \\
CSD length & $15.0 \pm 3.7(5.0-22.4)$ & $16.6 \pm 4.4(5.0-28.4)$ & .018 \\
CSD width & $6.0 \pm 2.0(2.5-11.3)$ & $6.2 \pm 2.6(1.6-21.0)$ & .619 \\
CSD depth & $2.9 \pm 1.1(1.0-6.0)$ & $2.5 \pm 1.2(0.5-10.1)$ & .033 \\
TRM & & & \\
\hline
\end{tabular}

$\mathrm{CS}=$ caesarean section; $\mathrm{CSD}=$ cesarean scar defect; $\mathrm{TRM}=$ thickness of the residual myometrium; TVS $=$ transvaginal sonography

Data presented as mean \pm SD (range) except for uterus position. Data presented as numbers (percentage) for uterus position.

Table S2 Clinical outcomes after treatment for cesarean scar defect

\begin{tabular}{|c|c|c|c|}
\hline Variable & Group A $(\mathrm{n}=50)$ & Group B $(n=228)$ & $P$ value \\
\hline $\begin{array}{l}\text { Hemoglobin on } \\
\text { the first postopera- } \\
\text { tive day } \\
(\mathrm{g} / \mathrm{L})\end{array}$ & $99.5 \pm 13.4(74.2-125.0)$ & $106.0 \pm 11.2(77.2-134.0)$ & .012 \\
\hline $\begin{array}{l}\text { Blood loss during } \\
\text { operation }(\mathrm{ml})\end{array}$ & $31.8 \pm 20.0(10-100)$ & $30.8 \pm 23.6(10-200)$ & .745 \\
\hline $\begin{array}{l}\text { Duration of surgical } \\
\text { procedure (min) }\end{array}$ & $57.0 \pm 11.8(30-90)$ & $55.9 \pm 9.4(25-99)$ & .497 \\
\hline $\begin{array}{l}\text { Length of hospital stay } \\
\text { (d) }\end{array}$ & $7.0(1.0)$ & $6.5(1.0)$ & $.296^{* *}$ \\
\hline $\begin{array}{l}\text { Hospitalization cost } \\
\text { (CNY) }\end{array}$ & $10870(2175.3)$ & $11085.0(1997.3)$ & $.528^{* *}$ \\
\hline \multicolumn{4}{|l|}{ Complications (n) } \\
\hline Bladder injury & $0(0.0 \%)$ & $2(.9 \%)$ & $.672^{*}$ \\
\hline Hematoma & $1(2.0 \%)$ & $2(.9 \%)$ & $.450^{*}$ \\
\hline
\end{tabular}

Data presented as mean \pm SD (range) except for complications, length of hospital stay and hospitalization cost, where complications presented as numbers (percentage) and length of hospital stay and hospitalization 
cost presented as median (interquartile range).

*: Fisher's Exact Test was used. **: Mann-Whitney U Test was used.

Table S3 Duration of menstruation and TRM before surgery and at 3,6 and median months after surgery

\begin{tabular}{llllll}
\hline & & Number of patients & Group A & $P$ value $^{*}$ & Group B \\
\hline Duration of menstruation & Before surgery & 231 & $15.4 \pm 4.1(5-20)$ & $<.001$ & $14.1 \pm 3.2(5-30)$ \\
& At 3 months & & $8.1 \pm 1.7(5-12)$ & & $8.1 \pm 2.5(3-18)$ \\
& Before surgery & 191 & $15.2 \pm 4.1(5-20)$ & $<.001$ & $14.2 \pm 3.2(5-30)$ \\
\multirow{2}{*}{ TRM } & At 6 months & & $8.3 \pm 2.0(5-15)$ & & $8.3 \pm 2.4(4-15)$ \\
& Before surgery & & $2.8 \pm 1.1(1.0-6.0)$ & $<.001$ & $2.4 \pm 1.0(.5-10.1)$ \\
& At median months & $7.6 \pm 2.8(2.0-12.0)$ & & $7.3 \pm 2.5(1.0-12.0$ \\
\hline
\end{tabular}

Data presented as mean $\pm \mathrm{SD}$ (range) for duration of menstruation and TRM before surgery and at 3, 6 and median months after surgery

*: The p-value compared the two time points (before surgery vs at 3 months, before surgery vs at 6 months, before surgery vs at median months) in each group.

Table S4 Comparison of $\mathrm{f}$ ollow-up data between two groups after treatment

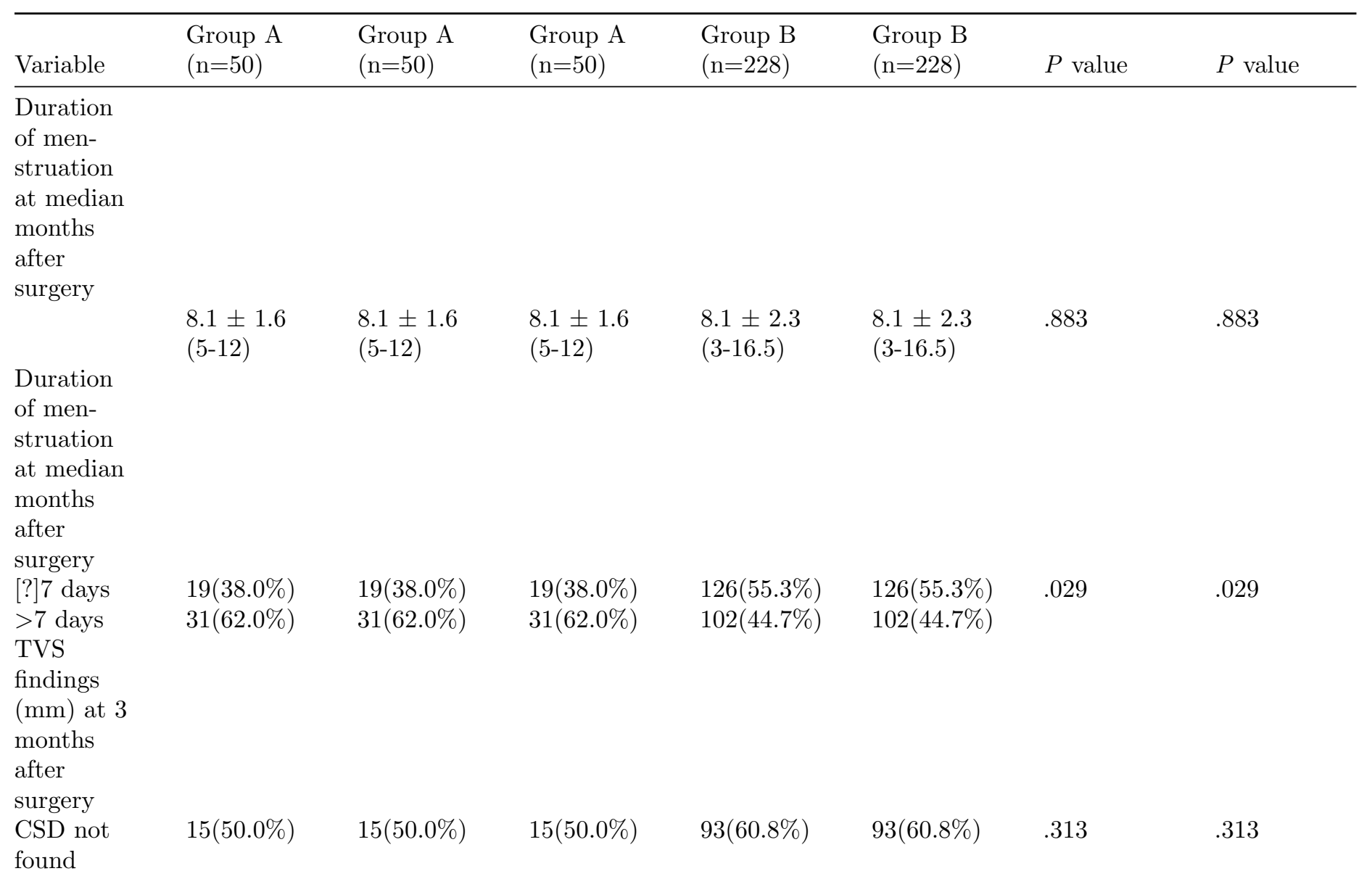




\begin{tabular}{|c|c|c|c|c|c|c|c|}
\hline Variable & $\begin{array}{l}\text { Group A } \\
(\mathrm{n}=50)\end{array}$ & $\begin{array}{l}\text { Group A } \\
(\mathrm{n}=50)\end{array}$ & $\begin{array}{l}\text { Group A } \\
(\mathrm{n}=50)\end{array}$ & $\begin{array}{l}\text { Group B } \\
(\mathrm{n}=228)\end{array}$ & $\begin{array}{l}\text { Group B } \\
(\mathrm{n}=228)\end{array}$ & $P$ value & $P$ value \\
\hline $\begin{array}{l}\text { CSD } \\
\text { found }\end{array}$ & $15(50.0 \%)$ & $15(50.0 \%)$ & $15(50.0 \%)$ & $60(39.2 \%)$ & $60(39.2 \%)$ & & \\
\hline $\begin{array}{l}\text { CSD } \\
\text { length }\end{array}$ & $\begin{array}{l}5.2 \pm 1.9 \\
(2-10)\end{array}$ & $\begin{array}{l}5.2 \pm 1.9 \\
(2-10)\end{array}$ & $\begin{array}{l}5.2 \pm 1.9 \\
(2-10)\end{array}$ & $\begin{array}{l}6.0 \pm 2.6 \\
(2-13)\end{array}$ & $\begin{array}{l}6.0 \pm 2.6 \\
(2-13)\end{array}$ & .281 & .281 \\
\hline $\begin{array}{l}\text { CSD } \\
\text { width }\end{array}$ & $\begin{array}{l}7.9 \pm 5.0 \\
(2-18)\end{array}$ & $\begin{array}{l}7.9 \pm 5.0 \\
(2-18)\end{array}$ & $\begin{array}{l}7.9 \pm 5.0 \\
(2-18)\end{array}$ & $\begin{array}{l}10.1 \pm 4.6 \\
(2-20)\end{array}$ & $\begin{array}{l}10.1 \pm 4.6 \\
(2-20)\end{array}$ & .878 & .878 \\
\hline $\begin{array}{l}\text { CSD } \\
\text { depth }\end{array}$ & $\begin{array}{l}5.8 \pm 3.4 \\
(2-11)\end{array}$ & $\begin{array}{l}5.8 \pm 3.4 \\
(2-11)\end{array}$ & $\begin{array}{l}5.8 \pm 3.4 \\
(2-11)\end{array}$ & $\begin{array}{l}5.7 \pm 3.4 \\
(2-21)\end{array}$ & $\begin{array}{l}5.7 \pm 3.4 \\
(2-21)\end{array}$ & .914 & .914 \\
\hline TRM & $\begin{array}{l}7.9 \pm 2.9 \\
(2.0-12.0)\end{array}$ & $\begin{array}{l}7.9 \pm 2.9 \\
(2.0-12.0)\end{array}$ & $\begin{array}{l}7.9 \pm 2.9 \\
(2.0-12.0)\end{array}$ & $\begin{array}{l}7.5 \pm 2.4 \\
(1.9-12.0)\end{array}$ & $\begin{array}{l}7.5 \pm 2.4 \\
(1.9-12.0)\end{array}$ & .460 & .460 \\
\hline $\begin{array}{l}\text { MRI } \\
\text { findings } \\
(\mathrm{mm}) \text { at } 6 \\
\text { months } \\
\text { after } \\
\text { surgery }\end{array}$ & & & & & & & \\
\hline $\begin{array}{l}\text { CSD not } \\
\text { found }\end{array}$ & $15(55.6 \%)$ & $15(55.6 \%)$ & $15(55.6 \%)$ & $71(63.4 \%)$ & $71(63.4 \%)$ & .655 & .655 \\
\hline $\begin{array}{l}\text { CSD } \\
\text { found }\end{array}$ & $11(44.4 \%)$ & $11(44.4 \%)$ & $11(44.4 \%)$ & $41(36.6 \%)$ & $41(36.6 \%)$ & & \\
\hline $\begin{array}{l}\text { CSD } \\
\text { length }\end{array}$ & $\begin{array}{l}6.5 \pm 6.1 \\
(1-13)\end{array}$ & $\begin{array}{l}6.5 \pm 6.1 \\
(1-13)\end{array}$ & $\begin{array}{l}6.5 \pm 6.1 \\
(1-13)\end{array}$ & $\begin{array}{l}4.2 \pm 3.3 \\
(1-13)\end{array}$ & $\begin{array}{l}4.2 \pm 3.3 \\
(1-13)\end{array}$ & .095 & .095 \\
\hline $\begin{array}{l}\text { CSD } \\
\text { width }\end{array}$ & $\begin{array}{l}8.7 \pm 7.6 \\
(3.0-16.0)\end{array}$ & $\begin{array}{l}8.7 \pm 7.6 \\
(3.0-16.0)\end{array}$ & $\begin{array}{l}8.7 \pm 7.6 \\
(3.0-16.0)\end{array}$ & $\begin{array}{l}7.9 \pm 5.5 \\
(3.0-22.9)\end{array}$ & $\begin{array}{l}7.9 \pm 5.5 \\
(3.0-22.9)\end{array}$ & .145 & .145 \\
\hline $\begin{array}{l}\text { CSD } \\
\text { depth }\end{array}$ & $\begin{array}{l}3.7 \pm 3.3 \\
(2.0-8.4)\end{array}$ & $\begin{array}{l}3.7 \pm 3.3 \\
(2.0-8.4)\end{array}$ & $\begin{array}{l}3.7 \pm 3.3 \\
(2.0-8.4)\end{array}$ & $\begin{array}{l}3.2 \pm 2.0 \\
(2.0-8.4)\end{array}$ & $\begin{array}{l}3.2 \pm 2.0 \\
(2.0-8.4)\end{array}$ & .966 & .966 \\
\hline TRM & $\begin{array}{l}5.7 \pm 2.9 \\
(3.2-9.6)\end{array}$ & $\begin{array}{l}5.7 \pm 2.9 \\
(3.2-9.6)\end{array}$ & $\begin{array}{l}5.7 \pm 2.9 \\
(3.2-9.6)\end{array}$ & $\begin{array}{l}4.8 \pm 2.3 \\
(1.2-9.9)\end{array}$ & $\begin{array}{l}4.8 \pm 2.3 \\
(1.2-9.9)\end{array}$ & .505 & .505 \\
\hline $\begin{array}{l}\text { TRM at } \\
\text { median } \\
\text { months } \\
\text { after } \\
\text { surgery by } \\
\text { MRI } \\
\text { Staging }\end{array}$ & $\begin{array}{l}7.6 \pm 2.8 \\
(2.0-12.0)\end{array}$ & $\begin{array}{l}7.6 \pm 2.8 \\
(2.0-12.0)\end{array}$ & $\begin{array}{l}7.6 \pm 2.8 \\
(2.0-12.0)\end{array}$ & $\begin{array}{l}7.3 \pm 2.5 \\
(1.0-12.0)\end{array}$ & $\begin{array}{l}7.3 \pm 2.5 \\
(1.0-12.0)\end{array}$ & .529 & .529 \\
\hline $\begin{array}{l}\text { Class-A } \\
\text { healing }\end{array}$ & $15(30.0 \%)$ & $15(30.0 \%)$ & $15(30.0 \%)$ & $\begin{array}{l}102 \\
(44.7 \%)\end{array}$ & $\begin{array}{l}102 \\
(44.7 \%)\end{array}$ & .038 & .038 \\
\hline $\begin{array}{l}\text { Non-class- } \\
\text { A } \\
\text { healing }\end{array}$ & $35(70.0 \%)$ & $35(70.0 \%)$ & $35(70.0 \%)$ & $\begin{array}{l}126 \\
(55.3 \%)\end{array}$ & $\begin{array}{l}126 \\
(55.3 \%)\end{array}$ & & \\
\hline
\end{tabular}

$\mathrm{CSD}=$ cesarean scar defect; TVS $=$ transvaginal sonography; TRM $=$ thickness of the residual myometrium

Data presented as mean \pm SD (range) for duration of menstruation and TRM at median months after surgery, CSD length, width, depth and TRM at 3 or 6 months after surgery. Data presented as numbers (percentage) for duration of menstruation at median months after surgery, TVS or MRI findings at 3 or 6 months after surgery and Class-A healing.

Table S5 Clinical characteristics of the women who achieved pregnancy without miscarriage 


\begin{tabular}{ll}
\hline Demographic & Patients $(\mathrm{n}=25)$ \\
\hline Age (y) & $31.0 \pm 3.6(27-38)$ \\
Number of cesarean deliveries (n) & 1 \\
Menstruation (d) & $13.4 \pm 3.3(7-20)$ \\
Before VR & $7.6 \pm 2.3(4-14)$ \\
After VR & \\
CSD size before VR (mm) & $8.8 \pm 3.0(2.9-13.3)$ \\
CSD length & $17.4 \pm 5.0(7.0-28.4)$ \\
CSD width & $6.3 \pm 2.1(2.7-10.2)$ \\
CSD depth & $2.3 \pm 0.8(0.5-4.0)$ \\
TRM & $32.0(8 / 25)$ \\
Persistent CSD after VR, \% & \\
CSD size after VR (mm) & $5.5 \pm 2.4(2.0-9.0)$ \\
CSD length & $7.8 \pm 2.3(5.0-11.0)$ \\
CSD width & $4.8 \pm 2.3(2.0-9.0)$ \\
CSD depth & $7.6 \pm 2.9(3.0-12.0)$ \\
TRM & $8.0(2 / 25)$ \\
Preterm birth rate (\%) & $3224.2 \pm 401.0(2400-4000)$ \\
Neonatal birth weight (g) & 10 \\
Apgar score (5 min) & $8.0(2 / 25)$ \\
Postpartum hemorrhage rate (\%) & $24.0(6 / 25)$ \\
adenomyosis rate (\%) &
\end{tabular}

$\mathrm{CSD}=$ cesarean scar defect; $\mathrm{VR}=$ vaginal repair; $\mathrm{TRM}=$ thickness of the residual myometrium

Data were presented as the means $\pm \mathrm{SD}$ or percentages

\section{Figure Legends}

Figure S1. MRI images of cesarean scar defects.

A. Sagital view on T2.B. Coronal view on T2.

Figure S2. Transvaginal surgery procedure.

The opening of the anterior peritoneal reflection; $\mathbf{B}$, the trimming of CSD edge; $\mathbf{C}$, the closing of the myometrium; and $\mathbf{D}$, the end of the procedure.

Figure S3. MRI scans of cesarean scar defects with adenomyosis.

A. Sagital view on T2 (retroflexed uterus).

B Sagital view on T2 (anteflexed uterus). 

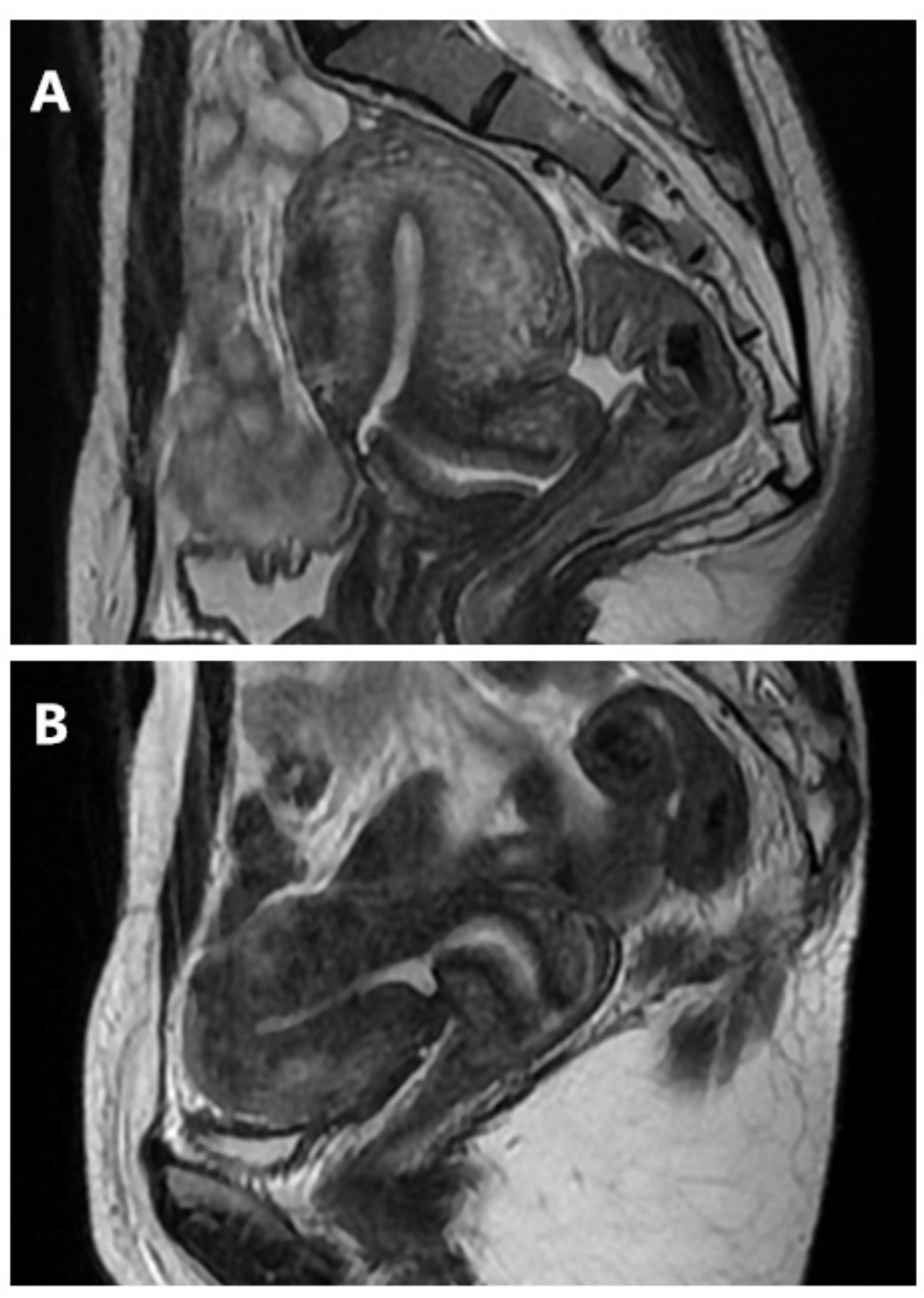

Figure S4. Obstetrical outcomes after vaginal repair of cesarean scar defects. 


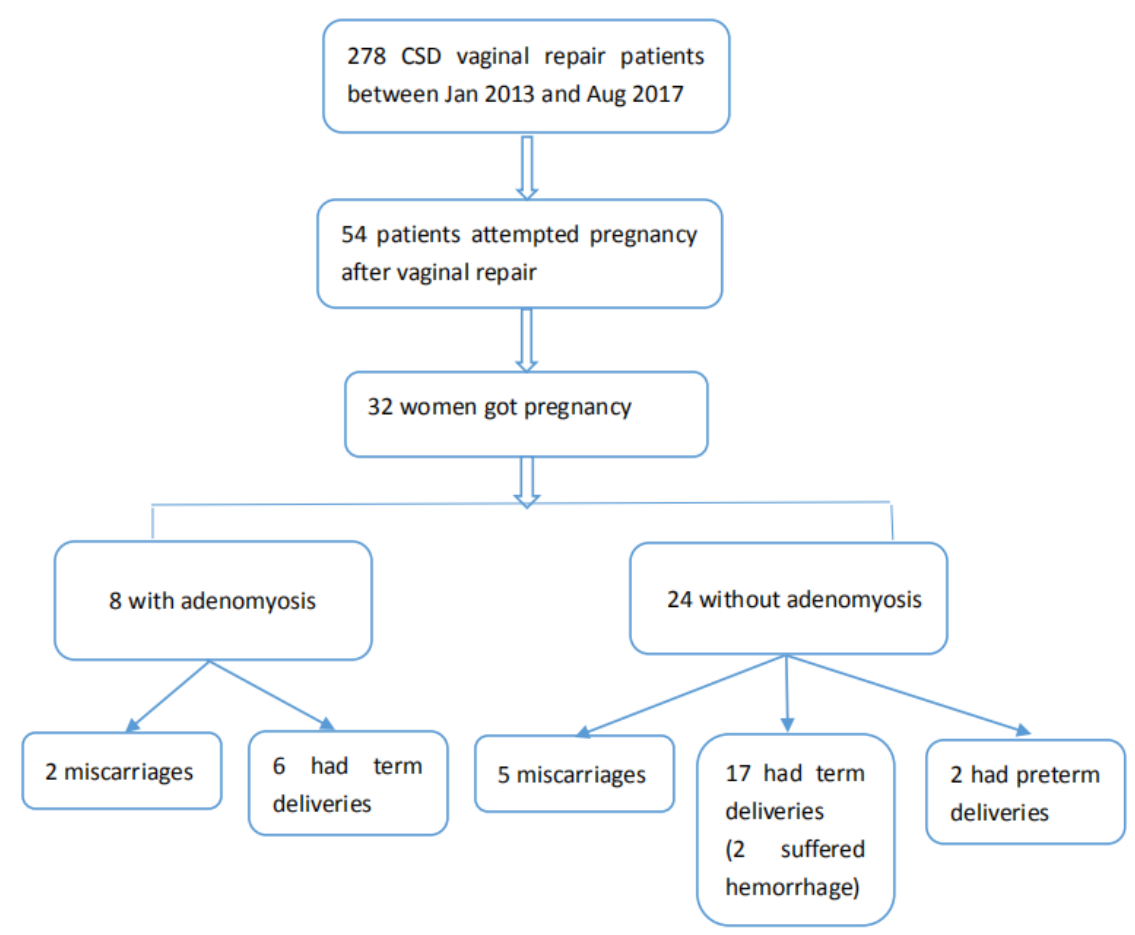



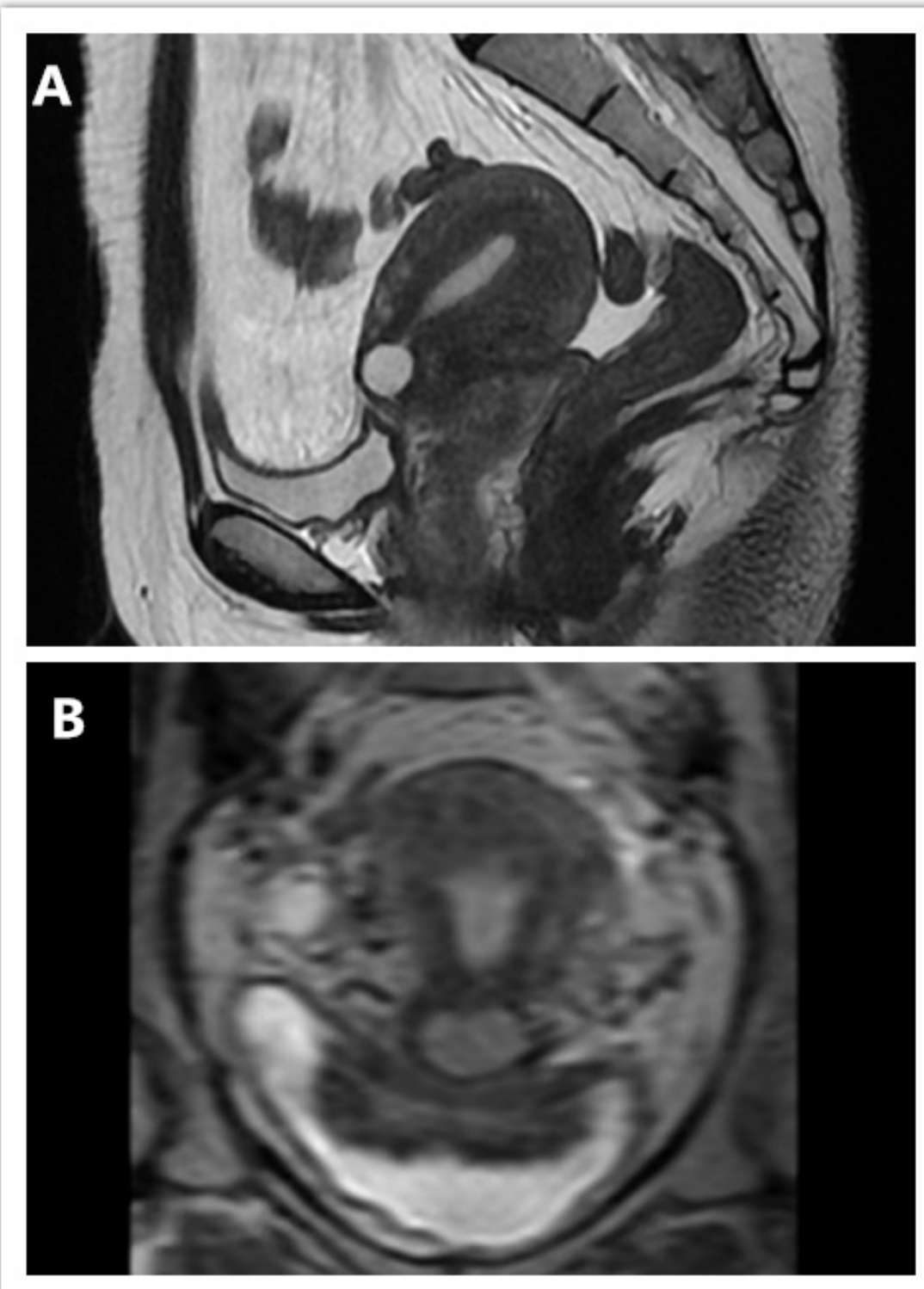

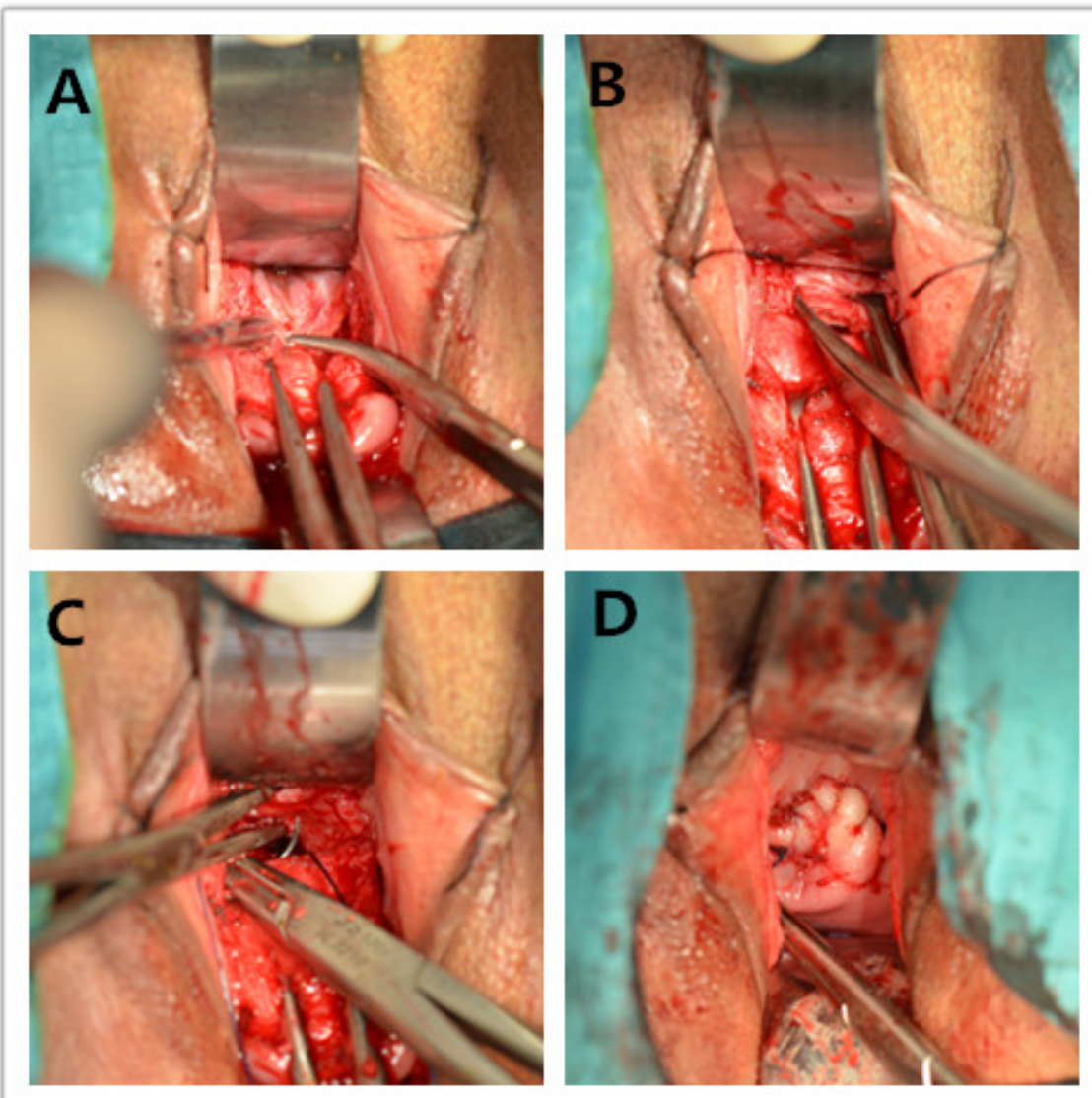

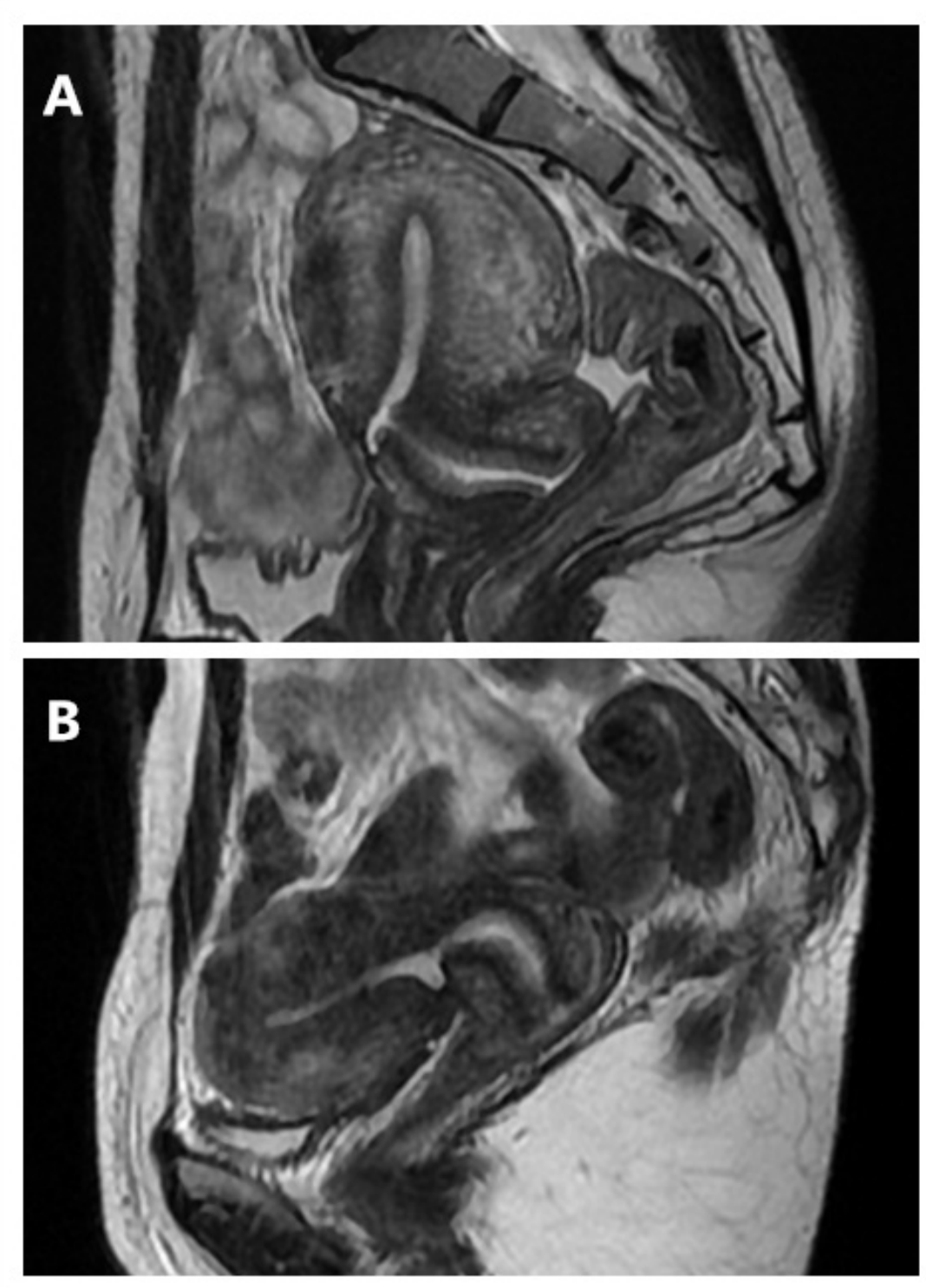


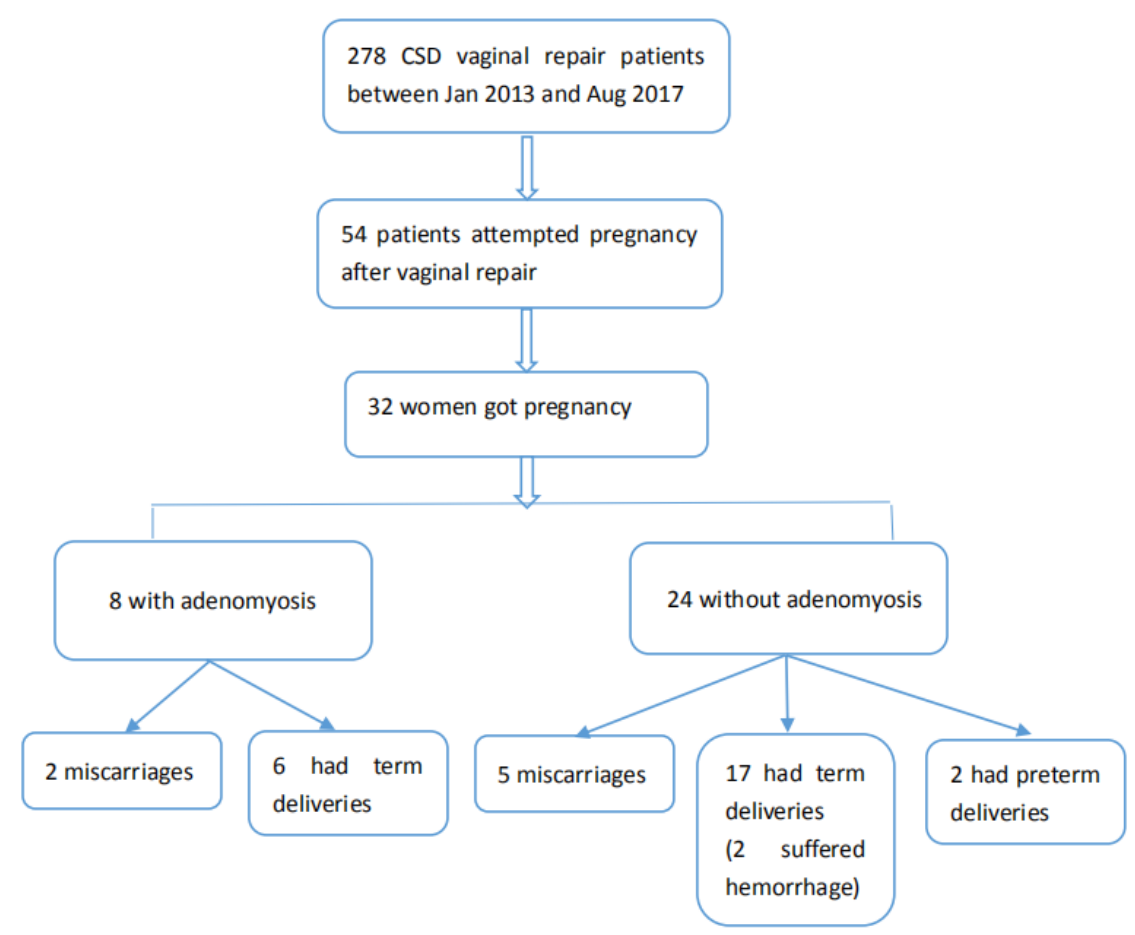

